\title{
O advérbio preposicional antes de em construções hipotáticas de realce não finitas
}

\section{The prepositional adverb antes de in hypotaxis constructions of enhancement non-finite}

\author{
Fábio Rodrigo Gomes da Costa* \\ fabiorodrigogc@yahoo.com.br \\ Universidade Federal do Rio de Janeiro \\ Marcos Luiz Wiedemer \\ m/wiedemer@gmail.com \\ Universidade do Estado do Rio de Janeiro
}

\begin{abstract}
RESUMO: Neste artigo, analisamos se as construções hipotáticas não finitas iniciadas pelo advérbio preposicional "antes de" podem atuar como estruturas de realce. Postulamos, com base em Halliday (2004, [1994]), que essas construções podem estar pospostas ou antepostas à oração matriz a depender da função comunicativa de realce. Os resultados demonstram que: (i) em vista das diferentes posições na sentença, as orações iniciadas com antes de são menos encaixadas na sentença, porém mais dependentes da oração matriz; (ii) o grau de desigualdade entre a oração matriz e a hipotática de realce é decorrente de esta última ser responsável por expandi-la ou ampliá-la a fim de apresentar uma relação circunstancial (tempo, efeito/resultado).
\end{abstract}

PALAVRAS-CHAVE: Advérbio preposicional. Construções hipotáticas. Realce. Abordagem construcional.

ABSTRACT: In this paper, we analyze whether the non-finite hypotaxis constructions initiated by the prepositional adverb "antes de" can act as enhancement structures. We postulate, based on Halliday (2004, [1994]), that the constructions can be placed after or before the matrix sentence depending on the communicative function of enhancement. The results demonstrate that: (i) in view of the different positions in the sentence, the sentences started with antes are less embedded in the sentence, but more dependent on the matrix sentence; (ii) the degree of inequality between the matrix sentence and the hypotaxis enhancement is due to the latter being responsible for expanding or extending it in order to present a circumstantial relation (time, effect/result).

KEYWORDS: Prepositional adverb. Hypotaxis constructs. Enhancement. Constructional approach.

\footnotetext{
* Doutorando em Língua Portuguesa pelo Programa de Pós-Graduação em Letras Vernáculas da Universidade Federal do Rio de Janeiro (UFRJ). Mestre em Estudos Linguísticos pelo Programa de Pós-graduação em Letras e Linguística da Universidade do Estado do Rio de Janeiro.

"Professor adjunto de Linguística da Universidade do Estado do Rio de Janeiro. Doutor em Estudos Linguísticos pela UNESP com estágio sanduíche na Universität Erfurt sob a supervisão do professor Christian Lehmann. Docente permanente do Programa de Pós-graduação em Letras e Linguística da UERJ/FFP.
} 


\section{Introdução}

O objetivo deste artigo é analisar, sob a ótica da Linguística CognitivoFuncional, nos termos de Traugott e Trousdale (2013), Bybee (2015) entre outros, e da perspectiva construcionista (GOLDBERG, 2006; CROFT, 2001; DIESSEL, 2015), as construções hipotáticas iniciadas com o advérbio preposicional "antes de", no português brasileiro, conforme o exemplo (01):

(01)

"Acordei antes do despertador tocar, beijei minha namorada na testa, lavei o rosto, me vesti, passei pela cozinha, peguei uma banana, guardei no bolso do casaco abri a porta da sala, chutei o jornal pra dentro, chamei o elevador, cumprimentei o porteiro, atravessei a rua e vim pra casa a pé".

[Folha de São Paulo, 09/07/17] ${ }^{1}$

A construção "antes de" é tradicionalmente classificada como locução prepositiva e, apesar de sua origem espacial, conforme demonstrado em Costa (2018), apresenta sentidos derivados (lugar, tempo, efeito/resultado), que são decorrentes da relação entre a construção e o cenário discursivo (frames). Em (01), portanto, a presença do advérbio preposicional "antes de" e de outros fatores contextuais, como verbos de ação e elementos com traços semânticos de concretude, acionam a noção de tempo expressa pelo advérbio preposicional na sentença. Assim, percebe-se que os fragmentos acima são narrativos, pois correspondem a uma sequência de fatos que apresentam uma ordem temporal. $O$ sintagma "antes do despertador tocar" evoca o frame de tempo e indica que o fato é posterior ao fato expresso na oração anterior, ou seja, obedece à ordenação linear. No entanto, a ação expressa pelo verbo "acordar" não é um efeito ou resultado da ação do verbo tocar.

Bergs e Diewald (2008) assinalam que a abordagem construcional da gramática assume que a língua consiste numa unidade simbólica convencional de pares de forma e sentido, e que essa relação pode ser tratada, com base na estrutura simbólica proposta por Croft (2001, p. 18), conforme disposto na Figura (1).

\footnotetext{
1 Todos os exemplos utilizados neste artigo são oriundos da dissertação de mestrado de Costa (2018).
} 
Figura 1: Propriedades de forma e sentido da construção

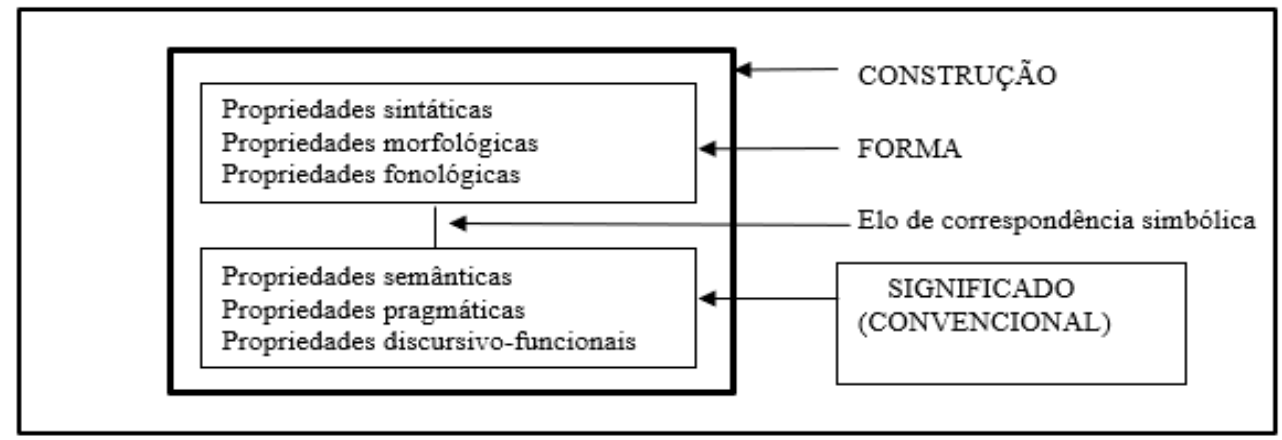

Assim, no modelo da Gramática de Construções, a língua, como outros sistemas cognitivos, é uma relação de "nós" e "ligações" entre eles; e a estrutura da linguagem é moldada pelo uso. Portanto, forma e significado devem ser considerados igualmente ao estudar a língua, ou seja, "a partir do pressuposto referido, a língua é concebida com uma extensa, complexa e interconectada rede de construções, em todos os níveis de análise linguística" (OLIVEIRA, 2019, p. 467). Com isso, as construções variam em um continuum de esquematicidade ou abstração. O termo aplica-se a ambas as unidades gramaticais que estão associadas a lexemas particulares e unidades gramaticais definidas sobre categorias abstratas, ou "slots", que podem ser preenchidos por certos tipos de expressões.

A construção "antes de", conforme defendido por Costa (2018), é uma categoria híbrida que apresenta traços de duas categoriais gramaticais: advérbio e preposição, denominada de "advérbio preposicional" por Costa (2018), em que a noção adverbial atua como modificadora (modo) e a noção preposicional (região espacial de/ponto de referência), conforme Wiedemer (2014, p. 117), "desempenham, (...) a função relacional. O relator, a preposição, faz a função de exprimir uma relação local entre o objeto localizado e um objeto de referência/ponto de referência. Com verbos que exigem um objeto localizado, que apresenta uma relação com um ponto de referência (...), ocorrem as preposições". Ainda, de acordo com Costa (2018), em um nível mais esquemático, os advérbios preposicionais são representados pelo esquema abstrato \{[XAdvYPrep] Adv. Prep.\}, em que temos: XAdv representa o significado abstrato/esquemático adverbial; e YPrep representa o significado abstrato/esquemático preposicional, e com isso, a representação abstrata [Adv. Prep.]. Esse esquema, que está em nível mais elevado da hierarquia 
construcional, licencia, em nível menos esquemático, os diferentes subesquemas construcionais, como: lugar, oposição, tempo, efeito/resultado, causa e concessão.

Ao avaliar as construções antes de, diante de, em frente a/de e em face de, Costa (2018) demonstrou que essas construções podem instanciar diferentes significados construcionais, que são decorrentes da categorização híbrida dos advérbios preposicionais, que são dependentes do contexto de uso (frame) e que são fixados os padrões construcionais [+preposicional], [ \pm preposicional/adverbial] e [+adverbial]. Assim, em contextos de usos mais locativos, mais a categoria preposicional é focalizada e em contextos de usos mais abstratos, mais a categoria adverbial é focalizada.

Além disso, Costa (2018) demonstrou que os advérbios preposicionais funcionam como instrumento de transposição, pois, os transpositores introduzem "estruturas que funcionam como modificadores com a mesma distribuição dos sintagmas adjetivos e dos sintagmas adverbiais" (AZEREDO, 1990, p. 38). Com isso, tais sintagmas podem ser oracionais ou não oracionais e, dentre os advérbios preposicionais analisados em Costa (2018), apenas o antes de introduz oração adverbial reduzida de infinitivo, que conforme proposta de Halliday (2004, [1994]), denominamos de construção hipotática de realce não finita.

Considerando que Costa (2018) encontrou diferentes padrões de usos para a construção "antes de", investigamos se as orações hipotáticas não finitas iniciadas por esse advérbio preposicional podem atuar como estruturas de realce (cf. HALLIDAY, 2004 [1994]). Nossa hipótese é de que tais orações podem estar pospostas ou antepostas à oração matriz a depender da função comunicativa. Em vista dessas diferentes posições na sentença, as orações iniciadas com "antes de" são menos encaixadas na sentença, porém mais dependentes da oração matriz. 0 grau de assimetria entre a oração matriz e a hipotática de realce é decorrente de esta última ser responsável por expandi-la ou ampliá-la a fim de apresentar uma relação circunstancial.

Para tanto, aplicamos a proposta de Halliday (2004 [1994]), no que concerne às relações semântico-funcionais e de dependência oracional. Como corpora de análise, utilizamos dados extraídos dos jornais Folha de São Paulo (https://www.folha.uol.com.br) e Estadão (http://www.estadao.com.br) ${ }^{2}$, por serem

\footnotetext{
${ }^{2}$ A coleta ocorreu entre os meses de julho e outubro de 2017 (ver COSTA, 2018).
} 
reconhecidamente vistos como jornais que apresentam linguagem formal e por apresentarem diversidade de gêneros e de seções.

O artigo se estrutura como a seguir: na próxima seção, apresentamos uma discussão sobre as estruturas de realce a partir da classificação disposta em Halliday (2004 [1994]), bem como abordamos dados extraídos da pesquisa de Costa (2018). Na sequência, apresentamos a proposta de análise do advérbio preposicional "antes de" em construções hipotáticas de realce não finitas. Por fim, a síntese e as referências.

\section{Estruturas de realce em construções hipotáticas}

Como estamos assumindo a ideia de fluidez de classes gramaticais a partir de uma perspectiva cognitivo-funcionalista, temos que reconhecer a categorização linguística em um continuum categorial. Sobre isso, Neves (2012, p. 110) comenta que o processo da "gradualidade existente no estabelecimento de categorizações é resultante do caráter fluido das fronteiras entre as categorias (a diluição das fronteiras)". Dessa forma, na literatura funcionalista (por exemplo LEHMANN, 1988; HALLIDAY, 2004 [1994]), os processos de articulação de orações são usualmente vistos a partir de graus de dependência/integração.

As propostas funcionalistas podem ser recuperadas no trabalho sobre gramaticalização de Hopper e Traugott (1993, p. 170), que reinterpretam as definições de complexidade oracional. De acordo com os autores, em todas as línguas, há mecanismos de interligação de orações, ou períodos compostos, que podem ser simplificados por meio de um continuum com, pelo menos, três pontos de aglomeração: parataxe (-encaixamento/-dependência) > hipotaxe (encaixamento/+dependência) > subordinação (+encaixamento/+dependência), sendo que a hipotaxe apresenta um núcleo e uma ou mais orações relativamente dependentes.

Aplicando essas definições a nosso objeto de análise, podemos compreender que as orações formadas com o advérbio preposicional "antes de" são, portanto, orações hipotáticas, pois é possível identificar os traços (-encaixamento) e (+dependência), conforme o exemplo (02): 
(02)

"Já na sala da magistrada, Alfredo imobilizou a vítima pelo pescoço, jogou produtos inflamáveis sobre si e no corpo dela e a forçou a dizer que ele era inocente. A todo o momento, ele ameaçava acionar um isqueiro com intenção de queimar a juíza. (...)

O suspeito, que fez curso técnico de química, também usava um capacete militar com a inscrição "inocente". Sua roupa tinha dizeres como 'fraude processual' escritos a mão. "Ele me confundiu com outra magistrada. Ele estava ali para passar por uma audiência do processo e não para perder a guarda do filho", disse a magistrada à época.

Santos era funcionário de uma confeitaria e, antes de atacar Tatiana Lima, tinha passagens pela polícia por crimes de menor potencial ofensivo.

[Folha de São Paulo, 04/07/17]

Em (02), a oração hipotática "antes de atacar Tatiana Lima" é menos encaixada, pois não apresenta posição fixa na sentença e é mais dependente, pois estabelece uma relação muito mais semântica do que sintática com a oração seguinte: "tinha passagens pela polícia por crimes de menor potencial ofensivo", ou seja, as passagens pela polícia em virtude de crimes de menor potencial ofensivo ocorreram em momento anterior ao ataque a Tatiana Lima. Assim, a relação entre a hipotática e a seguinte demonstra haver uma combinação de orações, tanto no que se refere à relação semântica quanto sintática. Nota-se uma relação semântica muito mais evidente, o que confirma o traço (+dependência) da hipotática.

O modelo de Hopper \& Traugott (1993) pode ser conjugado ao modelo de Halliday (2004 [1994]), no que concerne às relações semântico-funcionais e de dependência, que incluem a parataxe e a hipotaxe. Assim, o sistema da interdependência (conforme HALLIDAY, 2004 [1994]), ou sistema tático, inclui a parataxe e a hipotaxe e aplica-se a todos os complexos, sejam palavras, grupos, sintagmas ou orações. Hipotaxe é uma relação entre um elemento dependente e seu dominante, "a relação de elementos de diferentes estatutos"33 (HALLIDAY, 2004 [1994], p. 221) enquanto parataxe é uma "relação entre elementos de igual estatuto" $^{4}$ (p. 221), um iniciando e o outro continuando a sequência. As orações paratáticas, em princípio, são simétricas e transitivas, enquanto as hipotáticas são assimétricas e não transitivas. O autor afirma que a relação de interdependência entre duas orações pode ser tratada de igual estatuto, como em "Kukul se agachou no chão e se movia lentamente". E também assevera que a relação de interdependência entre duas orações pode ser tratada de forma desigual, como em "Quando ele veio para um matagal, ouviu o fraco farfalhar de folhas". É possível

\footnotetext{
${ }^{3}$ Cf. original: "the linking of elements of de unequal status" (HALLIDAY, 2004 [1994], p. 221).

${ }^{4}$ Cf. original: "the linking of elements of equal status" (HALLIDAY, 2004 [1994], p. 221).
} 
perceber que somente "ouviu o fraco farfalhar de folhas" constitui uma proposição, portanto pode ficar só, o que demonstra ser a oração matriz. "Quando ele veio para um matagal" não apresenta independência e, deste modo, é tratada como oração de qualificação da matriz. É interessante notar que a oração de qualificação pode estar antes ou depois da oração matriz. Deste modo, temos "Quando ele veio para um matagal, ouviu o fraco farfalhar de folhas" ou "Ouviu o fraco farfalhar de folhas quando ele veio para um matagal".

Retomando o exemplo (02), percebemos, quanto ao grau de interdependência, que há uma relação dessemelhante entre as orações. Assim, "antes de atacar Tatiana Lima" não constitui uma proposição, não apresenta, portanto, independência em relação à oração "tinha passagens pela polícia por crimes de menor potencial ofensivo". A oração "antes de atacar Tatiana Lima" constitui, portanto, a oração de qualificação da oração seguinte. E, por ser a de qualificação, não apresenta posição fixa na sentença, o que permite reescrevê-la da seguinte maneira: "tinha passagens pela polícia por crimes de menor potencial ofensivo antes de atacar Tatiana Lima".

Halliday (2004 [1994]) esclarece que os dois tipos de grau de interdependência, ou tático, são a parataxe, em que há uma relação de igualdade entre duas orações, e a hipotaxe, em que há uma relação desigual entre duas orações, ou seja, uma oração é dependente da outra. Assim, a parataxe e a hipotaxe caracterizam dois diferentes nexos entre orações. $O$ autor representa com a notação numérica $(1,2,3 \ldots)$ as estruturas paratáticas e com notação de letra grega $(\alpha, \beta \ldots)$ as estruturas hipotáticas. Enquanto na hipotaxe, os elementos são ordenados em dependência, na parataxe não há nenhuma dependência de qualquer elemento. Assim, retomando o exemplo (02), teríamos a seguinte representação:

Santos era funcionário de uma confeitaria e, antes de atacar Tatiana Lima, tinha 1 $\times 2 \beta$ passagens pela polícia por crimes de menor potencial ofensivo.

$2 \alpha$

Quanto às relações semântico-funcionais, que constituem a relação "lógica" das ideias nas línguas naturais, Halliday (2004 [1994]) afirma haver dois tipos gerais: (i) expansão e (ii) projeção, sendo: "Expansão: a cláusula secundária expande a cláusula primária por meio de elaboração, extensão ou realce. Projeção: a cláusula secundária é projetada através da cláusula primária, o que a instancia como (a) uma 
locução ou (b) uma ideia". 5 Além disso, entre as categorias de "expansão" e de "projeção", há subtipos: três de expansão e dois de projeção, conforme, abaixo:

(1a) Elaboração: uma cláusula expande outra, elaborando-a (ou uma parte dela): "reafirmando em outras palavras, especificando com mais pormenores, comentando ou exemplificando: "isto é, por exemplo". (1b) Extensão: uma cláusula expande outra, estendendo-a para além: adicionando alguma informação nova, apresentando uma exceção, ou oferecendo uma alternativa: "e, ou". (1c) Realce: uma cláusula expande outra, embelezando-a em torno dela: qualificandoa com alguma característica circunstancial de tempo, lugar, causa ou condição: "então, ainda, em seguida".

(2a) Locução: uma cláusula é projetada através de outra, que a apresenta como uma locução, uma construção de redação: "diz". (2b) Ideia: uma cláusula é projetada através de outra, que a apresenta como uma ideia, uma construção de sentido: "pensa". ${ }^{6}$

Além disso, os subtipos são representados, de acordo com Halliday (2004 [1994]), com as seguintes notações:

(i) Expansão: Elaboração = (sinal de igual); Extensão $+($ sinal de adição); Realce $\times$ (sinal de multiplicação). (ii) Projeção: Locução "(sinal de aspas duplas); Ideia ' (sinal de aspas simples). ${ }^{7}$

Halliday (2004 [1994]) esclarece que, enquanto na parataxe, somente a ordem $1 \wedge 2$ é possível, pois representa a ordem das orações na sentença; na hipotaxe, a oração secundária é sempre dependente e pode preceder a matriz $(\beta \wedge$ $\alpha)$ ou suceder a matriz $\left(\alpha^{\wedge} \beta\right)$. Desse modo, se invertêssemos a ordem da oração dependente, no exemplo (02), teríamos a seguinte representação:

\footnotetext{
${ }^{5} \mathrm{Cf}$. original: Expansion: the secondary clause expands the primary clause, by (a) elaborating it, (b) extending it or (c) enhancing it. Projection: the secondary clause is projected through the primary clause, which in states it as (a) a locution or (b) an idea. (HALLIDAY, 2004 [1994], p. 377).

${ }^{6}$ Cf. original: (1a) Elaborating: one clause expands another by elaborating on it (or some portion of it):'i.e., for example, viz.' restating in other words, specifying in greater detail, commenting, or exemplifying. (1b) Extending: one clause expands another by extending beyond it: adding some new 'and, or' element, giving an exception to it, or offering an alternative. (1c) Enhancing: one clause expands another by embellishing around it: qualifying it with 'so, yet, then' some circumstantial feature of time, place, cause or condition. (2a) Locution: one clause is projected through another, which presents it as a locution, 'says' a construction of wording. (2b) Idea: one clause is projected through another, which presents it as an idea, a 'thinks' construction of meaning (HALLIDAY, 2004 [1994], p. 378).

${ }^{7}$ Cf. Original: "(1) Expansion: elaborating = ('equals'); extending + ('is added to'). Enhancing $\times$ ('is multiplied by'). Projection: locution "(double quotes); idea (single quotes)" (HALLIDAY, 2004 [1994], p. 377).
} 
Santos era funcionário de uma confeitaria e tinha passagens pela polícia por crimes de 1 $2 \alpha$

menor potencial ofensivo antes de atacar Tatiana Lima. $\times 2 \beta$

No exemplo (02), entendemos que as orações "Santos era funcionário de uma confeitaria" e "tinha passagens pela polícia por crimes de menor potencial ofensivo" são independentes, pois cada uma constitui uma única proposição. Já a oração "Antes de atacar Tatiana Lima" estabelece uma relação de dependência com a oração seguinte "tinha passagens pela polícia por crimes de menor potencial ofensivo". Tal oração constitui uma hipotática de realce em vista de qualificar a oração seguinte com circunstância de tempo. ${ }^{8}$

Halliday (2004 [1994]) esclarece que a parataxe é a relação de elementos de igual estatuto, ou seja, ambos podem funcionar livres. Segundo o autor, na parataxe, a relação é (i) simétrica, assim 'sal e pimenta' implica 'pimenta e sal'; e (ii) transitiva, assim 'sal e pimenta', e 'pimenta e mostarda' implicam 'sal e mostarda'. Para o autor, conforme já indicado, a hipotaxe é a relação entre elementos de diferentes estatutos, ou seja, o elemento dominante é livre, mas o elemento dependente não é. Na hipotaxe, a relação é (i) não simétrica, assim em "Eu respiro quando durmo" não implica "Eu durmo quando respiro", e (ii) não transitiva, assim em "Eu me preocupo quando eu tenho de dirigir lentamente" e "Eu tenho de dirigir lentamente quando tem chovido" não implicam "Eu me preocupo quando tem chovido".

Halliday (2004 [1994]) menciona que, tanto na parataxe quanto na hipotaxe, as conjunções são usadas para marcar a oração dependente. No entanto, há diferenças entre as conjunções. Em orações não finitas, como em "antes de atacar Tatiana Lima", são utilizadas, segundo o autor, preposições conjuntivas. Denominamos o elemento "antes de" de advérbio preposicional e coadunamos com Costa (2018) a possibilidade de os advérbios preposicionais encabeçarem orações hipotáticas.

\footnotetext{
${ }^{8}$ Segundo Halliday (2004 [1994]), os principais papéis de transitividade são: processos, participantes e circunstâncias. Os processos codificam ações, eventos, relações entre entidades, expressam crenças ou sentimentos. Os participantes são as entidades que participam dos processos e, normalmente, têm a forma de sintagmas nominais, que são os argumentos. Já as circunstâncias consistem em informações extras relacionadas aos processos. Por meio da estrutura sintática, podemos relacionar ideias das mais simples até as mais complexas e também perspectivar uma situação de acordo com os propósitos comunicativos.
} 
Halliday (2004 [1994]) salienta que, na parataxe, a sequência de orações é tipicamente fixa $\left(1^{\wedge} 2\right)$, enquanto na hipotaxe a sequência é variável $\left(\alpha^{\wedge} \beta, \beta^{\wedge} \alpha\right)$. Assim como o autor, entendemos que o que determina a sequência é a escolha temática conforme exemplo:

$\alpha^{\wedge} \beta$ Frite a cebola até (ficar) ligeiramente marrom. de batata.

$\beta^{\wedge} \alpha$ Se você quiser um recheio mais substancial, adicione um pouco de purê

Além disso, explica que a sequência $\alpha^{\wedge} \beta$ é progressiva, ou seja, a oração dependente é de status remático. A fritura da cebola ocorre primeiro e, em seguida, ela muda de cor. Há, portanto, a iconicidade da sequência de orações com a sequência de eventos. Na sequência $\beta^{\wedge} \alpha$, a sequência é regressiva, ou seja, a oração dependente é de status temático. Assim, a oração dependente condicional é usada na reorientação do desenvolvimento do texto. No exemplo (02), podemos perceber que a relação entre as orações é regressiva:

$\beta^{\wedge} \alpha$ antes de atacar Tatiana Lima, tinha passagens pela polícia por crimes de menor potencial ofensivo.

Podemos perceber que a oração dependente contém a informação destacada em toda a notícia (o ataque a Tatiana Lima) e retoma o que já havia sido mencionado no texto (a imobilização feita na vítima e a ameaça em queimar o corpo dela). Trata-se, portanto, de informação dada, o que caracteriza seu status temático.

Halliday (2004 [1994]) afirma que, dentro do domínio de nexo clausal, as orações dependentes servem para configurar um contexto local no discurso e reorientar o desenvolvimento do texto. Por esse motivo, tais orações tendem a ser temáticas. No exemplo (02), reconhecemos que a oração "antes de atacar Tatiana Lima" apresenta status temático em vista de estabelecer a função de reorientação do desenvolvimento do texto, ou seja, retoma os atos cometidos pelo acusado. De acordo com o autor, algumas orações hipotáticas do tipo realce podem se basear no sistema de predicação de tema [theme predication]. Assim, orações de realce temporal podem ser predicadas para um primeiro plano, conforme Halliday (2004[1994]).

As orações hipotáticas de realce são conhecidas tradicionalmente como orações adverbiais e sua contribuição para o desenvolvimento do discurso é bem 
distinto das orações paratáticas. Na relação hipotática, a oração dependente pode se mover para um lugar distante da oração matriz. Enquanto na parataxe, as sequências de orações se movem para frente $(1,2,3 \ldots)$, na hipotaxe de realce, as sequências são textualmente distintas $\left(\alpha^{\wedge} \beta, \beta^{\wedge} \alpha\right)$.

Halliday (2004 [1994]) explica que as orações hipotáticas de realce podem ser finitas ou não finitas. Enquanto as finitas são introduzidas por uma conjunção subordinativa, as não finitas são introduzidas por preposição ou por um encadeador de subconjunto, tal como quando. O autor (HALLIDAY, 2004 [1994], p. 420) cita como exemplo de oração não finita:

III Siga os caminhos em torno dos jardins paisagísticos e para além das pontes || antes de descansar na casa de chá || onde o cheiro de flores de lótus se mistura com o do chá fresco e bolos tradicionais. $\|\left.\right|^{9}$

Na sentença acima, a oração hipotática de realce (antes de descansar na casa de chá) estabelece uma relação de tempo com a oração dominante (Siga os caminhos em torno dos jardins paisagísticos e para além das pontes). Segundo o autor, o elemento antes de, chamado de conjunção estrutural, estabelece a conexão entre as duas orações. Conforme já mencionamos, em nossa pesquisa, denominamos o "antes de" de advérbio preposicional e o incluímos entre os elementos que permitem iniciar orações hipotáticas de realce.

A partir dessa classificação oferecida por Halliday (2004 [1994]), analisamos se as construções hipotáticas não finitas iniciadas pelo advérbio preposicional "antes de" podem atuar como construções de realce. Para tanto, na seção seguinte, considerando os resultados da dissertação de Costa (2018) para os advérbios preposicionais, ofereceremos os resultados de nossa análise bem como dispomos a rede construcional dessas construções.

\section{Construções hipotáticas de realce não finita}

Em trabalho recente, Costa (2018) analisou os advérbios preposicionais antes de, diante de, em frente a(de) e em face de. Quanto ao advérbio preposicional antes de, considerando uma amostra de dados de 328 usos dessa construção, sendo 172 no jornal Folha de São Paulo e 156 no jornal Estadão, ao analisar as propriedades

\footnotetext{
${ }^{9}$ Cf. Original "II|Follow the pathways around the landscaped gardens and over bridges $\|$ before resting at the Tea House \|where the scent of lotus flowers mingles with that of freshly brewed tea and traditional cakes. |II" (HALLIDAY, 2004, p. 420).
} 
da forma e do sentido, o autor identificou nove possibilidades de usos (microconstruções). Dessas, quatro configurações permitem que o advérbio preposicional "antes de" introduza oração, o que denominamos de construção hipotática de realce não finita, a partir da classificação disposta por Halliday (2004 [1994]), conforme quadro (1).

Quadro 1: Microconstrução antes de (Fonte: adaptado de COSTA, 2018, p. 100)

\begin{tabular}{|l|l|}
\hline Microconstruções & \multicolumn{1}{c|}{ Relação Forma/Sentido } \\
\hline Microconstrução 1 & $\begin{array}{l}\text { Forma: oração matriz + advérbio preposicional antes de + oração hipotática } \\
\text { de realce não finita }\end{array}$ \\
\cline { 2 - 2 } & Sentido: tempo \\
\hline Microconstrução 2 & $\begin{array}{l}\text { Forma: advérbio preposicional antes de + oração hipotática de realce não } \\
\text { finita + oração matriz }\end{array}$ \\
\cline { 2 - 2 } & Sentido: tempo \\
\hline Microconstrução 3 & $\begin{array}{l}\text { Forma: oração matriz + advérbio preposicional antes de + oração hipotática } \\
\text { de realce não finita }\end{array}$ \\
\cline { 2 - 2 } & Sentido: efeito/resultado \\
\hline Microconstrução 4 & $\begin{array}{l}\text { Forma: advérbio preposicional antes de + oração hipotática de realce não } \\
\text { finita + oração matriz }\end{array}$ \\
\cline { 2 - 2 } & Sentido: efeito/resultado \\
\hline
\end{tabular}

Inicialmente, já é possível perceber a produtividade desse padrão construcional, que apresenta diferentes formas sintáticas, bem como diferentes sentidos. Sobre isso, Traugott e Trousdale (2013) aludem que os múltiplos significados disponíveis em uma rede irradiam de um protótipo ou significado central como extensões. Além disso, a organização de unidades linguísticas convencionais dentro de redes e conjuntos está intimamente relacionada ao uso da língua, tanto moldando-a, quanto sendo moldada por ela (LANGACKER, 2008).

Em (03), o advérbio preposicional "antes de" inicia oração hipotática de realce, que expande a oração matriz:

(03)

"As análises iniciais indicaram que o novo míssil Hwasong 14 seria capaz de atingir a maior parte do Alasca, e possivelmente o Havaí, se lançado em trajetória de ataque.

No teste, ele foi lançado em ângulo muito agudo, com o uso de uma técnica conhecida como "lofting" (arremesso vertical), e atingiu atitude de mais de $2.500 \mathrm{~km}$, antes de cair no oceano Pacífico a $930 \mathrm{~km}$ da Coreia".

[Folha de São Paulo, 06/07/17]

No exemplo (3), é possível identificar que "antes de cair no oceano Pacífico a 930 km da Coreia" estabelece uma relação de dependência com a oração anterior "e atingiu atitude de mais de 2.500 km". Esta última constitui uma proposição e se configura como oração matriz. Na relação entre as duas orações, o traço (+ dependência) é bem evidente, já que "cair no oceano Pacífico" é uma ação 
decorrente de "atingir altitude de mais de $2.500 \mathrm{~km}$ " e que, portanto, ocorre em momento posterior ao lançamento do míssil. As duas orações são estruturadas sem encaixamento, pois a oração dependente apresenta mobilidade sintática, o que consiste em uma relação de adjunção com a oração matriz. Assim, a oração "atingiu altitude de mais de 2.500 km" é hipotática, pois a relação entre as duas é de parcial integração, em que se notam os traços (+dependência) e (-encaixamento).

Em vista de a oração "antes de cair no oceano Pacífico a 930 km da Coreia" indicar a circunstância de tempo, pois indica momento posterior ao míssil atingir altitude de mais de $2.500 \mathrm{~km}$, podemos tratá-la como oração hipotática de realce, conforme Halliday (2004 [1994]). Além disso, podemos observar que a estrutura oracional obedece ao subprincípio da ordenação linear, ou seja, a ordenação das orações está de acordo com a sequência temporal dos eventos. Desse modo, "atingiu altitude de mais de 2.500 km" corresponde ao momento anterior e "cair no oceano Pacífico" corresponde ao momento posterior). A esse respeito, segundo Croft (1990 [2003], p. 204), "conceitos que são sempre, ou frequentemente, expressos por estruturas gramaticais simples são cognitivamente primitivos e aqueles expressos por estruturas complexas são cognitivamente complexos" 10 . Portanto, em (3), observamos que o advérbio preposicional "antes de" introduz oração hipotática de realce não finita, que constitui a oração dependente da matriz "atingiu altitude de mais de 2.500 km", conforme a seguinte representação:

$\alpha^{\wedge} \times \beta(\ldots)$ atingiu altitude de mais de $2.500 \mathrm{~km}$, antes de cair no oceano Pacífico a $930 \mathrm{~km}$ da Coreia.

Na sentença (04), ao contrário da sentença (03), a construção hipotática de realce encabeçada pelo advérbio preposicional "antes de" está anteposta à oração matriz, conforme a microconstrução 2:

(04)

"O presidente embarcou por volta das $13 \mathrm{~h} 20$ em um avião da Força Aérea Brasileira para Hamburgo. No G20, ele deve participar de reunião com chefes de governo estrangeiro e posar para a tradicional fotografia do encontro.

Antes de entrar na aeronave, Temer gravou um vídeo para as redes sociais fazendo um balanço da semana e transmitiu o cargo a Eunício na base aérea de Brasília".

[Folha de São Paulo, 06/07/2017]

\footnotetext{
${ }^{10} \mathrm{Cf}$. Original "concepts which are always, or frequently, expressed by simple grammatical structures are cognitively primitive and those expressed by complex structures are cognitively complex" (CROFT, 1990 [2003], p. 204).
} 
No trecho acima, podemos observar que a ordenação das orações corresponde a uma sequência regressiva, pois a oração dependente "antes de entrar na aeronave" tem status temático, ou seja, constitui informação já mencionada (embarcou em um avião da Força Aérea). A oração "antes de entrar na aeronave" apresenta circunstância temporal, ou seja, indica o momento em que o presidente Temer gravou um vídeo para as redes sociais. Ao observarmos a sentença (04), podemos ver, conforme Halliday (2004 [1994]), que as construções de qualificação podem preceder a oração matriz.

Neves et al. (2008) esclarece que as orações hipotáticas de tempo, quando antepostas à oração núcleo, estabelecem a orientação temporal para os eventos expressos posteriormente. Na sentença (04), observamos que a oração "antes de entrar na aeronave" precisa o momento em que Temer grava o vídeo. A autora acrescenta que, quando pospostas à oração núcleo, as orações hipotáticas de tempo delimitam a ação expressa na oração núcleo. Na sentença (03), "antes de cair no oceano Pacífico a $930 \mathrm{~km}$ da Coreia" determina o término da ação expressa na oração núcleo.

$\mathrm{Na}$ sentença (04), microconstrução 2, a oração hipotática de realce encabeçada pelo "antes de", anteposta à oração matriz, é representada da seguinte forma:

$x \beta^{\wedge} \alpha$ Antes de entrar na aeronave, Temer gravou um vídeo para as redes sociais (...)

Em (05), verificamos que a oração iniciada pelo advérbio preposicional "antes de" se distancia da noção de tempo marcado, conforme demonstrado nas sentenças anteriores:

(05)

"Tenho dinheiro do FGTS em ações de Petrobras e Vale. Posso sacar? Sim. Existem alternativas:

- Sacar apenas o dinheiro que está parado no FGTS e manter as ações. O dinheiro em ações poderá ser resgatado no futuro

- Retirar todo o dinheiro. Para isso, é preciso pedir o resgate ao banco que tem a custódia do investimento antes de sacar o FGTS inativo.

3. Como retiro o dinheiro

Depende de quanto tem em conta.

ONDE RECEBER O DINHEIRO".

[Folha de São Paulo, 03/07/2017] 
Na sentença em (05), podemos verificar que a ação "sacar o FGTS inativo" ocorre em momento posterior à ação expressa anteriormente em: "pedir o resgate ao banco". Assim, a microconstrução 3 encabeça oração reduzida de infinitivo, na qual o verbo denota ação posterior em relação à ação expressa pelo verbo da oração anterior. No entanto, as ações expressas não são factuais, ao contrário das apresentadas nas sentenças (03) e (04), ou seja, "cair no oceano Pacífico a 930 km da Coreia" e "entrar na aeronave" são ações ocorridas e estão, portanto, no plano factual. Na sentença (05), nota-se que as ações estão em um plano de ordem discursiva, já que o objetivo é orientar o leitor quanto aos procedimentos utilizados para realizar o saque do FGTS. Dessa forma, entendemos que a oração dependente "antes de sacar o FGTS inativo" não apresenta tempo marcado e, sim, discursivo. Portanto, entendemos que essa estabelece com a oração matriz (pedir o resgate ao banco) uma relação de efeito/resultado, já que, de acordo com a orientação do autor do texto, é necessário, primeiro, pedir o resgate ao banco para, enfim, sacar o FGTS. Além disso, os textos injuntivos são reconhecidos por serem incitadores de ações, o que também justifica o uso da construção "antes de" com ideia de efeito/resultado.

É possível notar que a posição da oração hipotática é motivada por fatores/atributos presentes no paradigma discursivo (região funcional/enquadre cognitivo com especificações que servem de orientação para o uso da língua), que passa a orientar a formulação de expressões linguísticas. De acordo com Leino \& Östman (2005, p. 200), "um padrão de discurso é o correlato cognitivo do tipo de texto definido linguisticamente e o gênero definido socioculturalmente. A compreensão do texto e do discurso ocorre principalmente em termos de padrão discursivo". ${ }^{11}$

Entendemos que "Retirar todo o dinheiro" é retomado anaforicamente, na frase seguinte, pelo pronome "isso" e pela oração hipotática, que foi posta ao final da frase para reafirmar a ação destacada. Desse modo, verificamos que a oração hipotática funciona como um adendo de uma sentença de finalidade. O autor, portanto, privilegiou a sentença de finalidade/propósito introduzida pelo "para" com o intuito de reorientar a frase, deixando para o final da frase a hipotática de realce com

\footnotetext{
${ }^{11}$ Cf. Original: "A discourse pattern is the cognitive correlate of the linguistically defined text type, and the socioculturally defined genre. Understanding of text and discourse takes place primarily in terms of discourse pattern" (LEINO; ÖSTMAN, 2005, p. 200).
} 
valor de efeito/resultado. Reconhecemos, desse modo, que a oração hipotática de realce encabeçada pelo advérbio preposicional antes de, microconstrução 3 , está posposta à oração matriz (pedir o resgate ao banco), conforme demonstrado adiante:

$\alpha^{\wedge} x \beta(\ldots)$ é preciso pedir o resgate ao banco que tem a custódia do investimento antes de sacar o FGTS inativo.

Já na sentença (06), microconstrução 4, é possível verificar que a oração hipotática de realce está anteposta à oração matriz.

(06)

"Nem sempre pagar aluguel é jogar dinheiro fora. Em alguns casos, locar um imóvel em vez de comprá-lo pode ser mais vantajoso financeiramente. Mas, antes de fazer a escolha, é preciso analisar uma série de variáveis.

Para quem já tem o montante suficiente para comprar à vista, o primeiro critério a ser analisado é o tempo de permanência no imóvel".

[Folha de São Paulo, 09/07/2017]

Em (06), podemos ver que a oração hipotática de realce, assim como na sentença (05), estabelece com a oração matriz (analisar uma série de variáveis) uma relação de efeito/resultado, pois não se deve, de acordo com o texto, fazer a escolha sem antes analisar uma série de variáveis. A sequência de orações é regressiva, pois a oração dependente possui status temático, já que marca o início do parágrafo a fim de emoldurar primeiro a decisão final do leitor e depois fornecer os critérios a serem analisados antes da tomada de decisão. O autor chama a atenção para a oração matriz "analisar uma série de variáveis", por isso ela se encontra em posição remática. A oração "antes de fazer a escolha" não constitui informação nova, já que faz referência à informação de locação de imóvel, o que também justifica sua posição temática.

Em (05) e em (06), percebemos que ambos são trechos injuntivos, cujo propósito é apresentar sequências imperativas que visam à realização de uma ação. Nota-se, portanto, que a tipologia textual favorece o uso de oração que expressa a noção de efeito/resultado. Conforme Costa (2018), foi possível constatar que o advérbio preposicional antes de, no sentido de efeito/resultado, apresenta propriedades mais adverbiais que preposicionais em vista de inserir-se em contextos mais discursivos ou mais abstratos. 
Em (06), identificamos que a oração hipotática de realce está anteposta à dominante, conforme a representação a seguir:

$x \beta^{\wedge} \alpha(. .$.$) antes de fazer a escolha, é preciso analisar uma série de variáveis.$

Nas ocorrências (03), (04), (05) e (06), foi possível perceber que a posição e a função das orações hipotáticas são interdeterminantes. A posição anteposta ou posposta à dominante não é motivada por fatores estilísticos e, sim, por fatores/atributos presentes no paradigma discursivo. Assim, nas construções temporais, as antepostas são usadas para precisar o momento de uma determinada ação e as pospostas são usadas para delimitar uma ação. Nas construções de efeito/resultado, as antepostas são usadas para reorientar o desenvolvimento do texto e as pospostas, para reafirmar ações destacadas anteriormente e/ou para apresentar adendo de sentença de finalidade.

Foi possível observar, ao analisarmos as ocorrências de (01) a (06), que, com exceção de (01), o sujeito da hipotática de realce é zero. Desse modo, a presença do sujeito não é tão significativa nas orações dependentes. Isso nos ajuda a comprovar que a oração hipotática de realce constitui a circunstância da ação expressa na oração matriz.

Conforme percebemos até aqui, os usos da construção com antes de são produtivos e apresentam uma vasta gradiência semântica. Aqui é importante destacar a questão da gradiência entre os subesquemas, isto é, há uma diferença entre os subesquemas, no que diz respeito a algumas das propriedades do significado - semântica, pragmática e discurso -, e que dificultam enquadrá-los unicamente em uma ou outra construção. Tendo em vista essa gradiência, as categorias e unidades da língua são variáveis, em vez de categorias fortemente delimitadas (BYBEE, 2003). Desse modo, reafirmamos que a categorização de unidades linguísticas está relacionada às representações, ou esquemas simbólicos, existentes na língua.

O modelo da Gramática de Construções, além de postular a relação entre os polos forma/significado, propõe, em uma perspectiva sincrônica, que a língua é formada por um inventário de construções que se organizam hierarquicamente em torno de uma rede taxonômica comum. Dessa forma, a língua é entendida, por este modelo, como uma rede de nós interligados por elos que se estabelecem de 
maneira hierárquica (LANGACKER, 1987). Tal rede taxonômica é formada por padrões mais específicos e por padrões mais esquemáticos. $\mathrm{E}$ a gramática, dessa maneira, consiste na organização da convivência de todos esses padrões.

Encontramos quatro padrões construcionais de usos, que são representados pelas microconstruções (ver Quadro 1) formadas com "antes de", que estão em um grau de esquematicidade menor dentro de uma hierarquia construcional, pois apresentam diferenças de estruturação sintática no polo da forma. Porém, observando os sentidos semântico-discursivos, eles estão, no nível intermediário, representados por duas mesoconstruções, que instanciam as noções de tempo e efeito/resultado, estando relacionadas ao esquema abstrato da Construção Advérbio Preposicional, conforme representado na figura (02).

Figura 2: Rede construcional da construção hipotática de realce com "antes de"

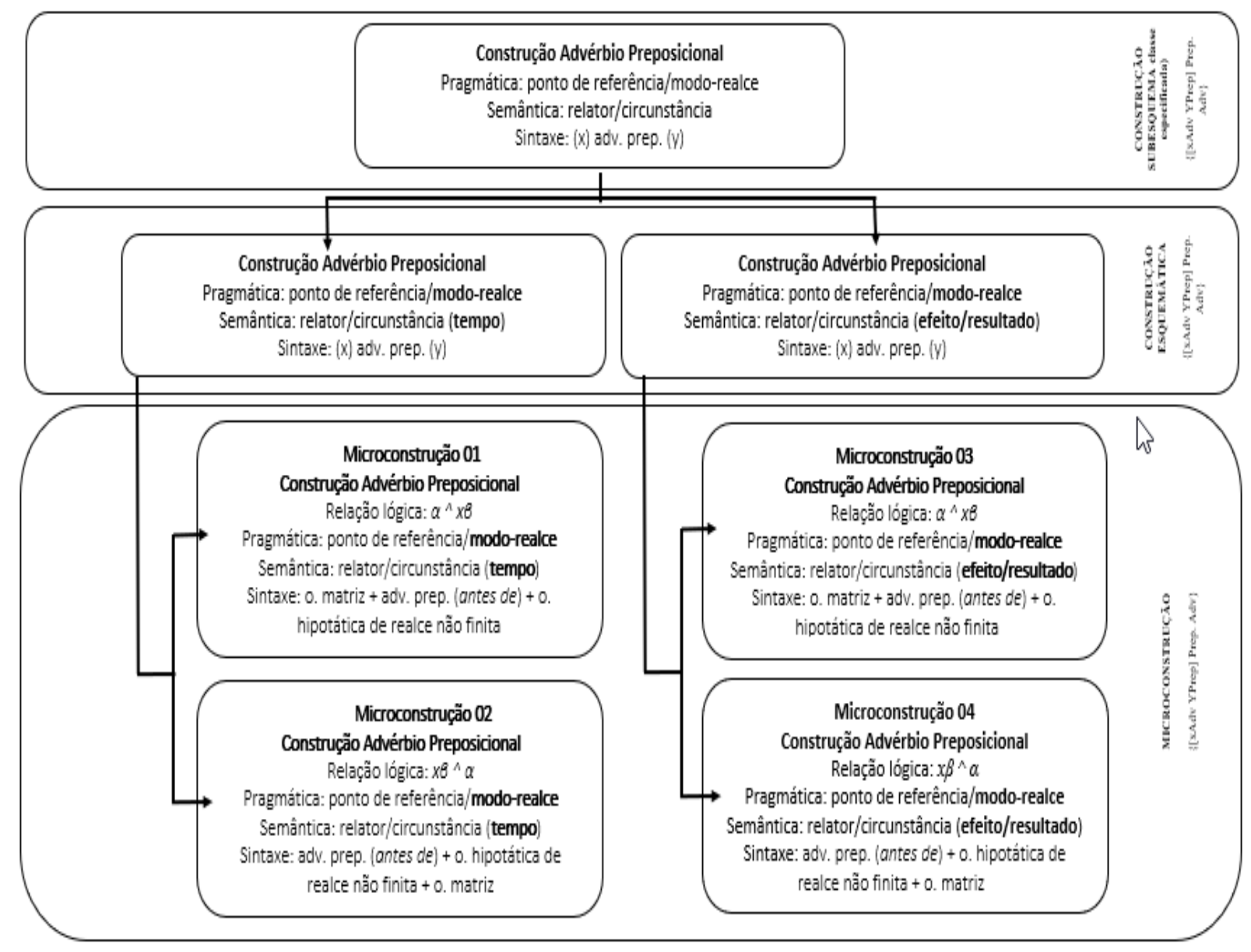

Na Figura (2), temos: no nível da macroconstrução, a construção advérbio preposicional, que licencia sentidos preposicionais (ponto de referência) e adverbiais (modo); no nível da mesoconstrução, encontramos dois subesquemas (tempo e 
efeito/resultado). Já as microconstruções decorrentes demonstram que, em cada uma das noções semânticas (tempo e efeito/resultado), há duas possibilidades no nível da forma: uma em que a cláusula hipotática está anteposta à oração matriz e outra em que a cláusula hipotática está posposta à oração matriz.

Assim, vimos que cada microconstrução analisada apresenta configurações de sentido/forma diferentes em sua realização. Acreditamos que cada padrão de uso para a construção "antes de" é decorrente da função comunicativa, ou seja, a hipotática de realce é responsável por expandi-la ou ampliá-la a fim de apresentar uma relação circunstancial, seja de tempo, seja de efeito/resultado. Também observamos que o advérbio preposicional estabelece uma relação (relator) entre um elemento e outro, traço este que é próprio das preposições. Quanto à natureza adverbial, identificamos a possibilidade de mobilidade dos sintagmas encabeçados pelo advérbio preposicional, que ora podem estar no início de uma sentença ora podem estar no fim.

Soma-se que o advérbio preposicional que indica noção de tempo (microconstruções 1 e 2 ) tem como função estabelecer uma localização temporal. Esta é, no entanto, mais abstrata que a localização espacial. A espacialização do tempo é, conforme Batoréo (2000), um dos fenômenos mais correntes e mais evidentes na linguagem. Desse modo, expressões locativas, como os advérbios preposicionais, também compõem a base das expressões temporais. Identificamos que o advérbio preposicional, para localizar no tempo, além de conectar elementos não oracionais, também pode conectar orações.

A noção temporal é bastante evidente no advérbio preposicional "antes de" em vista de o elemento "antes", isolado, ser um advérbio de tempo. A possibilidade de os advérbios de tempo estarem em diferentes posições em uma sentença também é um traço marcante nos advérbios preposicionais. Assim, vemos que a circunstância de tempo e a mobilidade na sentença, além da possibilidade de estabelecer uma relação com um referente temporal e de conectar elementos na sentença, permitem que possamos observar os advérbios preposicionais como elementos que apresentam tanto componentes adverbiais quanto preposicionais. Já o advérbio preposicional que indica efeito/resultado, diferente da noção de tempo, possui natureza mais adverbial que preposicional. Assim, a ação expressa no sintagma formado pelo advérbio preposicional antes de não funciona como um marcador temporal, mas, sim, como uma ação que resulta de outra ação. Portanto, 
trata-se de circunstância percebida no nível textual, pois a ação anterior é condição para que outra ação ocorra posteriormente.

É importante salientar que a noção de tempo está presente nos significados construcionais [tempo] e [efeito/resultado]. No entanto, é fundamental entendermos a diferença entre tempo marcado e tempo discursivo a fim de percebermos a diferença entre os dois significados. Na noção de efeito/resultado, a noção de tempo é inferida na sequência lógica do texto. Assim, a ação motivadora precede outra ação que ocorre em seguida e que é percebida como efeito/resultado da outra. Reconhecemos como tempo discursivo a noção temporal existente na relação entre a ação motivadora e a ação decorrente. Já o tempo marcado, é aquele que visa localizar temporalmente uma determinada ação. O tempo marcado ocorre em construções nas quais podemos identificar o significado construcional [tempo].

Retomando a definição de Halliday (2004 [1994]) para as estruturas de realce, vimos que uma oração hipotática expande a oração matriz, qualificando-a em relação de tempo ou efeito/resultado, ou seja, dando-lhe uma circunstância/modo. Além disso, vimos que, a depender da função comunicativa, a posição da hipotática apresenta diferentes composições sintáticas, o que comprova o traço [encaixamento] desse tipo de construção. Por outro lado, vimos que há uma relação lógico-semântica entre as orações que compõem essa construção, o que comprova o traço [+dependência].

\section{Considerações Finais}

No presente trabalho, pudemos demonstrar as diferentes microconstruções formadas com o advérbio preposicional antes de e comprovar que este pode estabelecer a conexão entre uma oração dependente e sua matriz. Assim, quanto ao grau de interdependência ou táxis, as orações iniciadas com antes de apresentam uma relação desigual com a oração matriz, ou seja, são dependentes desta. E, quanto à relação lógico-semântica, tais construções expandem a oração matriz, qualificando-a. Tais orações iniciadas com o antes de são, portanto, orações hipotáticas de realce não finitas, que, segundo Neves et al. (2008, p. 938), "expandem as nucleares, reelaborando-as, ampliando-as ou apresentando uma relação circunstancial”. 
Procuramos demonstrar que as quatro microconstruções expressam diferentes propósitos comunicativos. Assim, a microconstrução 1 apresenta oração hipotática de realce posposta à dominante a fim de delimitar a ação expressa na oração matriz. A microconstrução 2, anteposta à dominante, visa precisar o momento de uma determinada ação. A microconstrução 3 apresenta oração hipotática de realce que visa reafirmar ação destacada antes e/ou apresentar adendo de sentença de finalidade. E a microconstrução 4, anteposta à matriz, é usada para reorientar o desenvolvimento do texto.

Ao evidenciarmos as relações contextuais, que motivam o uso das construções adverbiais preposicionais, postulamos que os falantes compreendem e fazem uso de constructos emoldurados a frames que são recorrentes na interação verbal; e que os esquemas de construções mais entrincheirados são os mais propensos a serem selecionados para a formação de uma nova construção. Isso requer que coloquemos em relação os dois polos do conhecimento: linguagem e cognição. Assim, a adoção da noção de esquemas de relação lógico-semânticos, conforme proposto por Halliday (2004 [1994]), como esquemas conceptuais, seja como esquemas interacionais, se mostrou produtiva neste estudo. De acordo com esse raciocínio, em uma rede, determinada construção pode ser composta por (alguns) itens lexicais diferentes dos de outra construção, e tais itens podem, enquanto microconstrução, formar um ambiente particular de uso.

\section{Referências}

AZEREDO, J. C. Iniciação à sintaxe do português. Rio de Janeiro: Jorge Zahar Ed., 1990.

BATORÉO, H. J. Expressão do espaço no português europeu. Lisboa: Fundação para a Ciência e Tecnologia/Fundação Calouste Gulbenkian, 2000.

BERGS, A.; DIEWALD, G. (Eds.) Constructions and Language Change. Berlim: Mouton de Gruyter, 2008.

BYBEE, J. Language Change. Cambridge: Cambridge University Press, 2015.

COSTA, F. R. G. Os advérbios preposicionais antes de, diante de, em frente a/de em face de: gradiência e fixação de padrões construcionais. Dissertação (Mestrado em Estudos Linguísticos), UERJ, 2018.

CROFT, W. Typology and universals. 2. ed. (Cambridge textbooks in linguistics). Cambridge University Press, 1990 [2003]. 
CROFT, W. Radical Construction Grammar: syntactic theory in typological perspective. Oxford: Oxford University Press, 2001.

DIESSEL, H. Usage-based linguistics. In.: DABROWSKA, E.; DIVJAK, D. (Eds.). Handbook of Cognitive Linguistics, 2015, p. 295-321.

GOLDBERG, A. Constructions at work: the nature of generalization in language. Oxford: Oxford University Press, 2006.

HALLIDAY, M. A. K. An Introduction to Functional Grammar. London: Hodder Arnold, 2004 [1994].

HOPPER, P.; TRAUGOTT, E., Grammaticalization. Cambridge: Cambridge University Press, 1993.

LANGACKER, R. W. Foundations of Cognitive Grammar: theoretical prerequisites, v. 1. Stanford University Press, 1987.

LANGACKER, R. W. Cognitive Grammar: A Basic Introduction. New York: Oxford University Press, 2008.

LEHMANN, C. Towards a typology of clause linkage. In.: HAIMAN, J.; THOMPSON, S. A. (Eds.) Clause combining in grammar and discourse. Amsterdam/Philadelphia: John Benjamins Publishing Company, p. 181-225, 1988.

LEINO, L.; ÖSTMAN, J-O. Constructions and variability. In.: FRIED, M.; BOAS. H. C. Grammatical Constructions: back to the roots. Amsterdam/Philadelphia: John Benjamins Publishing Company, 2005, p. 192-213 (Constructional Approaches to Language).

MOURA NEVES, M. H. et al. As Construções hipotáticas. In.: ILARI, R.; MOURA NEVES, M. H. (Org.). Gramática do português culto falado no Brasil. Campinas, SP: Editora da Unicamp, p. 937-1015, 2008.

OLIVEIRA, M. R. Sintaxe do português em perspectiva construcional: propriedades e desafios. Revista Estudos Linguísticos, v. 48, n. 1, p. 455-483, 2019.

TRAUGOTT, E. C.; TROUSDALE, G. Constructionalization and Constructional Changes. Oxford: Oxford University Press, 2013.

WIEDEMER, M. L. Para uma visão conceptual das preposições que complementam verbos de movimento no português brasileiro. Veredas, v. 18, n. 2, p. 102-122, 2014. 